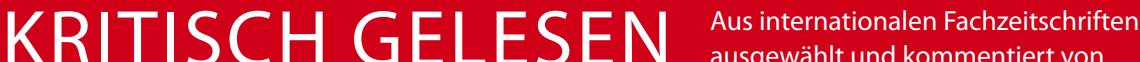

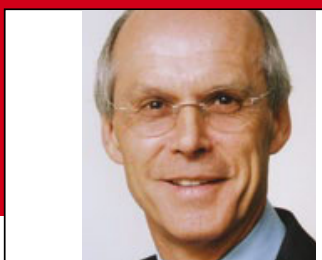

Prof. Dr. med. H. S. FüeßI Isar-AmperKlinikum, KI. München-Ost, Haar

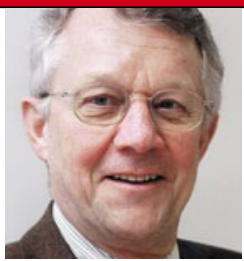

Prof. Dr. med. H. Holzgreve Internist, Kardiologische Praxis, München

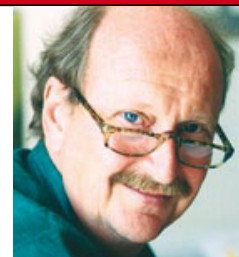

Prof. Dr. med.

E. Ernst

Peninsular

Medical School,

University

of Exeter/UK

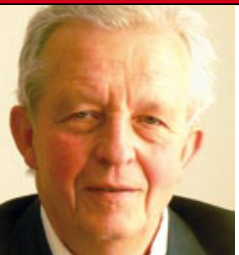

Prof. Dr. med. K. Malberg Immunologie, DresdenLoschwitz

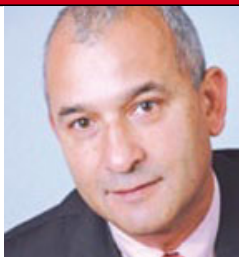

Prof. Dr. med. T. F. Schwarz

Juliusspital Würzburg

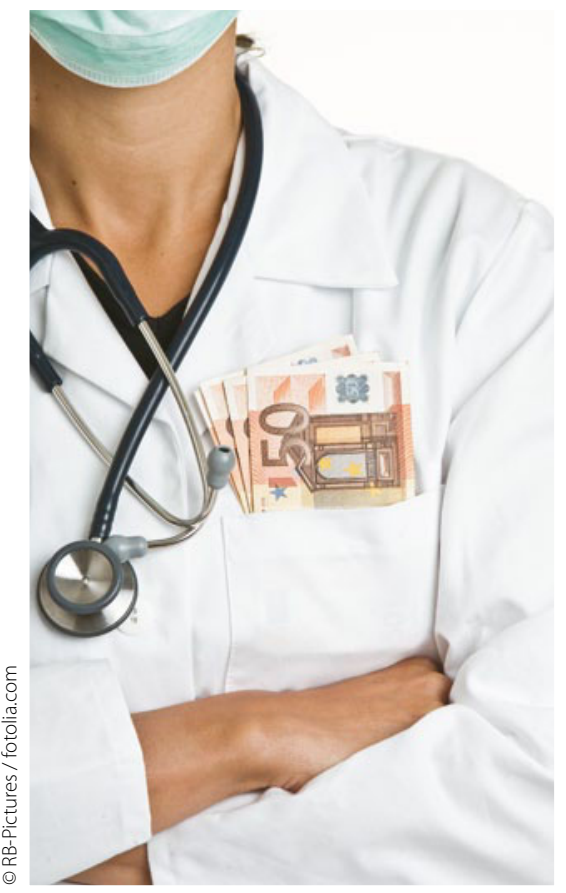

Interessenkonflikte werden nicht immer korrekt gemeldet.

\section{Interessenkonflikte und die Glaubwürdigkeit von Leitlinien}

\section{Die Experten, die die Leitlinien an- erkannter Organisationen und Fach- gesellschaften formulieren, haben oftmals finanzielle Verbindungen mit der Industrie, aber häufig werden diese Konflikte nicht offen gelegt.}

- Die Autoren werteten Leitlinien zum Thema Hyperlipidämie und Diabetes aus, die von Regierungsorganisationen, nationalen Fachgesellschaften, Ärztegesellschaften oder anderen Non-profit-Organisationen in den USA und in Kanada zwischen 2000 und 2010 herausgegeben wurden. Ein „Interessenkonflikt“ war definiert als finanzielle Zuwendung für Forschungsarbeiten, Vorträge und Beratung bzw. Aktienbesitz von Firmen, die einschlägige Medikamente vertreiben.
Von 288 Experten, die an 14 Leitlinien beteiligt waren, hatten 150 (52\%) einen Interessenkonflikt. Dieser wurde von zwölf Teilnehmern verschwiegen. Auch jeder zweite Vorsitzende der Leitlinienkommissionen hatte einen Interessenkonflikt.

138 (48\%) bekannten sich zu einem Interessenkonflikt, während 150 dies verneinten oder angaben, keine Gelegenheit zur Erklärung erhalten zu haben. Bei acht von 73 Experten, die einen Interessenkonflikt verneinten, konnten die Autoren solche nachweisen. An den von Regierungsorganisationen geförderten Leitlinien hatten deutlich weniger Mitwirkende einen Interessenkonflikt als bei jenen von Nicht-Regierungsorganisationen (16 vs. 69\%).

\section{Kommentar}

Diese Analyse dokumentiert die Verbreitung von Interessenkonflikten und weckt Zweifel an der Unabhängigkeit und Objektivität bei der Erstellung von Leitlinien. Kann man dieses Problem lösen? Es wird vorgeschlagen, dass an der Formulierung von Leitlinien nur Experten ohne finanzielle Konflikte mitwirken. Aber dann werden gerade die einflussreichen und erfolgreichen Fachver- treter ausgeschlossen, an denen die Industrie besonders interessiert ist, und der Beraterkreis engt sich erheblich ein. Zitieren wir den Emeritus E. A. M. Gale: „Wir müssen die Realität der Welt, in der wir leben, erkennen. Die akademische und nicht-akademische Medizin ist durchdrungen von Interessenkonflikten, und viel zu viele profitieren von dieser Situation, um dies öffentlich zu machen. Die
Gesetzgebung wird dieses Problem nicht beseitigen, weil das schnelle Geld immer einen Schritt voraus ist."

H. HOLZGREVE

\section{-J. Neumann et al.}

Prevalence of financial conflicts of interest among panel members producing clinical practice guidelines in Canada und United States: cross sectional study. Brit. med. J. 343 (2011) d5621 